\title{
Research on price index measurement: Agendas for the next twenty years
}

\author{
Edited by Ernst R. Berndt
}

MIT Sloan School of Management, Cambridge, MA 02142, USA

NBER, Cambridge, MA 02138, USA

\section{Background}

The year 1999 has marked twenty years since Martin Feldstein asked Zvi Griliches, and Zvi agreed, to head up a new NBER Program on Technological Change and Productivity Measurement. Over the last two decades, one of the important research emphases of this NBER program has been a focus on price and output measurement. As part of the twentieth anniversary and during the NBER's 1999 Summer Institute, Ernst Berndt and Zvi Griliches convened a panel of price index specialists to present their individual views on what research agendas they would propose as meriting highest priority over the next twenty years.

Individuals asked to make formal panel presentations on July 21, 1999, at the NBER Productivity Program of the Summer Institute, included: Charles Schultze (Brookings Institution, Chairman of the Council of Economic Advisors under President Carter, and recently named to chair a National Academy of Sciences Panel on the Conceptual, Measurement and Other Statistical Issues in Developing Cost of Living Indexes); Zvi Griliches (Harvard and NBER); Katharine Abraham (Commissioner of the US Bureau of Labor Statistics); W. Erwin Diewert (University of British Columbia and NBER); Brent Moulton (Associate Director for National Income, Expenditure and Wealth Accounts, US Bureau of Economic Analysis, and formerly Director of the Office of Research on Prices and Living Conditions at the US Bureau of Labor Statistics); and Jack Triplett, Brookings Institution, and formerly Chief Economist at the US Bureau of Economic Analysis). In addition to those making formal presentations, a number of other individuals present at the panel session participated by making comments and raising related issues.

After the panel session, Ernst Berndt asked each of the formal presenters to write up his/her remarks. Except for those of Charles Schultze, these edited remarks follow. Note that the comments by Zvi Griliches were not written up; they have been transcribed from notes taken by Ernst Berndt, and Zvi was not able to review them. 
Comments by Zvi Griliches

Harvard University and NBER, Cambridge, MA, USA

Let me begin by stating that I believe it is time to forget about old battles, and instead ask, where do we go from here? The difficult tasks facing us we must do immediately, although the impossible ones may take some time.

I think it is important we congratulate the Bureau of Labor Statistics for undertaking, disseminating and publishing a great deal of very important price index research over the last twenty years. Both through the NBER's Program on Technological Progress and Productivity Measurement, and through the joint NBER - Conference on Research in Income and Wealth conferences and workshops, there have been extensive interactions among the government statistical community that creates and publishes price statistics, and users of these statistics in academia and in the public and private sectors. We all benefit from these interactions, and it is important they continue and grow.

In general, I agree with most of the remarks by Charles Schultze. In particular, I think it is important to take into account the fact that different price indexes can and will be used for different purposes. While construction and publication of different indexes may be feasible for the BLS today, publication of multiple indexes can create political difficulties. For example, if the BLS published a large number of price indexes (more than it does now), which, if any, would be suitable for cost-of-living adjustments for Social Security payments? In my Congressional testimony at the time of the Boskin Commission report, I spoke about problems with using the current $\mathrm{CPI}$ as a measure for indexing Social Security payments, and suggested that median nominal income per capita or per household may be a more appropriate index. This is an important issue for research, one that needs more attention in the near future.

There are two big remaining questions on which research should focus. The first is the difficult one, and concerns boundaries. What is the commodity and consumer space over which prices are measured? Among other issues, here I think it is important to recognize the link between BLS price measures and the GDP accounts at the BEA, and that there should be consistency between national accounts and price measures. Two examples come to mind. The first involves treatment of auto emission controls. If the costs of mandated auto emission controls are taken into account when the BLS creates price indexes for, say, automobiles, then the quantity benefits of these controls should show up somewhere in the national GDP accounts. The second example of consistency issues involves the medical area. Here the additional issue is that the BLS prices only the out of pocket payments by consumers in its medical CPI, plus making a general health insurance adjustment based on insurers' retained earnings. However, there is no price index that measures the "purchases" and purchase prices paid by third party payers, such as private insurance companies and governments. In the GDP accounts, there is an attempt to measure the real output of the medical sector, but the price indexes used to deflate expenditures are not right. There's a 
big need to focus on conceptual and practical consistency issues between BLS price measurement and the BEA's GDP measurement.

The impossible topic is quality change. Medical price measurement is again an example of the very difficult issues we face. Research needs to focus on the implications for price measurement of heterogeneity in access to medical care (now even available on the internet); how the absence of a free market affects the valuation, diffusion and use of medical technology; how to incorporate the value of life into price index calculations evaluating the benefits of new products and procedures that decrease mortality; and how the presence of various comorbidities affects both marginal benefit and marginal cost calculations. There is considerable room for reasonable discussion and debate concerning choice of boundaries in assessing quality change, and I think there is good reason to encourage construction and publication of various experimental price indexes, by BLS and others. As an example outside the medical care area, you might ask yourself if GDP should be unaffected whether Apollo landed and safely returned to earth, or not?

Over the longer term, I would like to see price index researchers begin to incorporate more of the research from the non-economics community. One example is the outcomes and cost-effectiveness research from medical and health policy researchers. Another involves environmental data. Data sets need to be expanded to encompass both economic and non-economic measurement.

I would also like to see the launching of a research institute devoted to researching price measurement topics, jointly funded by the BEA and the BLS, and with a strong institutional support not only from them, but also from the NSF. 
Comments by Katharine G. Abraham

US Bureau of Labor Statistics, Washington, DC, USA

Were experts in the field to be polled, I believe there would be substantial agreement among them regarding the most fundamental problems of price and quantity measurement. One major problem area is service sector measurement. Measurement can't begin without an output definition, and, for many services, there is no consensus regarding the appropriate definition. Customization of output is an important complication. If no two customers purchase exactly the same product, what rules can be used for defining the output that has been produced? This isn't a problem that is restricted to the service sector - it long has been important in construction and may be increasingly important in goods production more generally - but it certainly is a very serious problem for service sector measurement. Additional conceptual problems arise because, as has been noted by Zvi Griliches [7], the output of a service activity like medical care or teaching depends critically on consumers' characteristics and the nature of their participation in the service delivery process. More globally, price and quantity measurement are complicated by technical change, which may lead both to changes in the characteristics of goods and services and to the development of wholly new goods and services.

The nature of these problems is such that no general solution to them is possible. Rather, much of the work to improve our price and output measures must proceed on an industry-by-industry, product-by-product basis. That's not to say there won't be spillovers from studies in one industry or product that inform thinking about another, but rather that each ultimately will require individual analysis.

Perhaps the best way for me to contribute to this discussion of priorities for research on price and output measurement is to talk about the research currently being done at, or supported by, the Bureau of Labor Statistics (BLS), particularly research that relates to the fundamental problems I alluded to a moment ago. I should acknowledge that the agenda implicit in this research probably is not a 20 -year agenda. By and large, the projects in which we're investing are projects that we would hope might pay off in the form of improved measurement methods that could be implemented within the next five to ten years.

One important thing we're involved in that might not generally be considered research is a major interagency - indeed, international - effort to develop a comprehensive product classification structure [11]. In addition to staff from the BLS, the Bureau of Economic Analysis (BEA) and the Bureau of the Census, Canada and Mexico also are engaged in this effort, which follows work done to develop the new North American Industry Classification System. I mention product classification in the present context for the reason that, if done well, a service sector product classification structure will go a long way towards defining the output of the service sector in an operationally useful fashion.

Secondly, as part of the Consumer Price Index (CPI) Improvement Initiative for which the BLS first received funding in 1998, we are working to expand the use of 
hedonic quality adjustment methods in the construction of the CPI. Hedonic methods already are used in producing the CPI housing, apparel, television, and computer indexes. We are working to develop hedonic models for a range of additional products. Those selected for model development work in 1999 include telephones, VCRs, DVD players, camcorders, refrigerators, microwave ovens, washers, dryers and audio products [5]. In each case, it remains to be seen whether an acceptable hedonic model can be developed, but that is our goal.

Thirdly, in the medical care arena, working collaboratively with National Bureau of Economic Research (NBER) researchers, we are exploring the use of third-party databases to identify shifts in hospital treatment patterns that may affect what we should be pricing [3]. Under standard Producer Price Index (PPI) procedures, a hospital procedure selected for pricing would continue to be priced until the next time the survey sample was redrawn. In this case, however, we are seeking a way to identify new treatments that are now competing with older treatments and, where such new treatments can be identified, to begin substituting toward them in our pricing sample to reflect their current period usage. An important part of this work will be deciding whether and how to compare the prices of the old and the new treatments in constructing our measure of hospital services price change. I might add that, more generally, the BLS has been a significant financial supporter of NBER research on measurement of medical care prices.

We also are seeking to support research on price measurement in other challenging sectors. For example, we plan to commission outside research on telecommunications services that will address such questions as the appropriate output concept for this industry, the best treatment of frequently changing service plans, and indicators that might be useful for tracking changes in the quality of the service offered. To take another example, we hope to commission outside research on college education prices. That research would explore strategies for capturing transaction prices (tuition less the value of the financial aid package) rather than list prices (tuition), as well as possible approaches to adjusting for changes in the quality of the educational product.

A final important area of BLS research activity relates to the use of scanner data [2]. We currently are engaged in a test effort to produce real-time CPIs for certain products in certain geographic areas (specifically, in the first instance, breakfast cereals in the New York metropolitan area) using scanner data as an alternative to data collected by our field economists. So far, that test seems to be going well. Ultimately, of course, scanner data should be helpful for dealing with shifts in product mix and the emergence of new products.

The above list outlines work that is relevant to addressing at least a piece of the challenge I outlined at the beginning of my comments. I've omitted a substantial amount of work we're doing or supporting on less glamorous things where, it turns out, there also is plenty to be done. That includes work on things such as small sample bias in index number construction and seasonal adjustment in cases where quantities sold are highly seasonal even though prices may not be (see, for example [4,10]). We're also engaged in research in a number of related areas, including the development 
of inter-area cost of living indexes, democratic (person-weighted) as compared to plutocratic (dollar-weighted) indexes, and the construction of separate indexes for population subgroups (see, for example $[1,6,8,9]$ ).

Although there is a substantial amount of research work underway at the BLS on a fairly wide range of issues, our in-house resources are limited, as are the resources of our colleagues at BEA and the Census Bureau. With so much to be done, there is certainly ample scope for useful academic research on fundamental price and quantity measurement problems. Indeed, we at the statistical agencies are counting on your help. From my perspective, there are two broad areas in which academic research can be particularly helpful. First, given the importance of case-by-case analysis, there is great need for careful studies of individual industries and products. Second, because the programmatic uses of BLS data push us to focus on improvements to our current data collection methods, we devote relatively little effort to historical research. Our energy goes principally into the development and implementation of new, and hopefully improved, methods, rather than towards asking how our view of the past might have been affected had those new methods been adopted earlier. This obviously is something the BEA must deal with, but their research resources are even more limited than those of the BLS. Academic research oriented towards producing better historical price and output series could fill an important void.

\section{References}

[1] N. Amble and K. Stewart, Experimental Price Index for Elderly Consumers, Monthly Labor Review 117 (May 1994), 11-16.

[2] R. Bradley, B. Cook, S.G. Leaver and B.R. Moulton, An Overview of Research on Potential Uses of Scanner Data in the US CPI. Paper presented at the Third Meeting of the International Working Group on Price Indexes, Washington, DC, April 1997, pp. 16-18.

[3] Bureau of Labor Statistics, Medical Care Quality Adjustment Initiative in the Producer Price Index. Unpublished document. Washington, DC, 1999.

[4] W.E. Diewert and R.C. Feenstra, International Trade Price Indexes and Seasonal Commodities. Report to the Bureau of Labor Statistics. Washington, DC, 1999.

[5] D. Fixler, C. Fortuna, J. Greenlees and W. Lane, The Use of Hedonic Regressions to Handle Quality Change: The Experience in the US CPI. Paper presented at the Fifth Meeting of the International Working Group on Price Indexes, Reykjavik, Iceland, August 25-27, 1999.

[6] T.I. Garner, D.S. Johnson and M.F. Kokoski, An Experimental Consumer Price Index for the Poor, Monthly Labor Review 119 (September 1996), 32-42.

[7] Z. Griliches, Introduction, in: Output Measurement in the Service Sector, Z. Griliches, ed., University of Chicago Press, Chicago, 1992, pp. 1-22.

[8] M.F. Kokoski, An Alternative Aggregation for Price Indices: Democratic versus Plutocratic Indices. Working paper. Bureau of Labor Statistics, Washington, DC, 1997.

[9] M.F. Kokoski, B.R. Moulton and K. Zieschang, Interarea Price Comparisons for Heterogeneous Goods and Several Levels of Commodity Aggregation. Bureau of Labor Statistics Working Paper No. 291, Washington, DC, 1996.

[10] R. McClelland and M. Reinsdorf, A Note on Estimating Small Sample Bias in Two Price Index Formulas. Working paper. Bureau of Labor Statistics, Washington, DC, 1997.

[11] Office of Management and Budget, Economic Classification Policy Committee; Initiative to Create a Product Classification System, Phase 1: Exploratory Effort to Classify Service Products. Federal Register, April 16, 1999, pp. 18984-18989. 
Comments by Erwin Diewert ${ }^{1}$

Department of Economics, University of British Columbia, Vancouver, Canada

NBER, Cambridge, MA, USA

\section{Introduction}

When Ernie Berndt approached me to participate in this panel discussion, I agreed but at the same time, I thought that it was slightly ridiculous to be looking ahead for twenty years. With the current very rapid pace of technological change, it is difficult to look ahead two years, let alone twenty years. However, when I reflected on our topic, research in the measurement of prices and quantities, I changed my mind. Many of the "new" developments in the measurement of prices over the past twenty or thirty years took twenty years or more to be implemented. Let me give some examples:

- The Stigler [44] Commission, which examined the price statistics of the US government, advocated probability sampling for collecting price quotations at the lowest level of aggregation. The Bureau of Labor Statistics did not implement this suggestion until 1978 (and virtually all other countries still do not use probability sampling).

- In a chapter in the Stigler report, Zvi Griliches [24] updated the hedonic research of Court [9] on adjusting automobile prices for quality change and suggested that statistical agencies should use the hedonic regression technique more widely to adjust prices for quality change. ${ }^{2}$ This suggestion was not adopted until the 1980 's. $^{3}$

- Many years ago, Hicks [29, p. 114] introduced the idea of a shadow price or a reservation price that would ration the consumer to demand zero units of a new product in the period prior to its introduction. This reservation price could then be inserted into an index number formula and the usual bilateral index number theory could be extended (in theory) to deal with the new goods problem. However, the practical problem is: how are we to determine this

\footnotetext{
${ }^{1}$ Written version of an oral presentation at the NBER Summer Institute Productivity Program, July 21, 1999, Cambridge MA at the session: "Research in Price, Quality and Quantity Measurement: What Agenda for the Next Twenty Years? A Panel Discussion". Some of the material in this paper was published in "Price Index Research in the Coming Decades: Conference Report", by K. Abraham, E. Berndt, W.E. Diewert, Z. Griliches, B. Moulton, C. Schultz and J. Triplett, Monthly Labor Review, September 2000, 33-36, Bureau of Labor Statistics, Washington D.C.

${ }^{2}$ The concept of a hedonic regression dates back to F. Waugh [50] but the term hedonic is due to Court [9].

${ }^{3}$ See Cole et al. [8], Triplett [45-48], Dulberger [22] and Silver [43]. For an accessible review of the hedonic literature, see Chapter 4 of Berndt [3, p. 102-149], "The Measurement of Quality Change: Constructing an Hedonic Price Index for Computers using Multiple Regression Methods”.
} 
shadow price? Diewert [14, p. 501-503] suggested some econometric methods for this determination but actual empirical implementations of this class of methods for dealing with new commodities did not occur until very recently; see Hausman [26,27].

- Diewert [13] wrote his first paper on superlative indexes in $1973^{4}$ but it took about 20 years for the idea to diffuse into statistical agencies; see Triplett [48] and Young [51]. ${ }^{5}$

- The Australian economist, P. Lloyd [31], derived an exact index number formula for the Constant Elasticity of Substitution (CES) utility function, which depended only on based period expenditure shares, prices in the two periods under consideration and an estimate of the elasticity of substitution between all commodities in the index. Many years later, B. Moulton [32] independently derived this index number formula and realized that it could be used to form a close approximation to a superlative index using basically the same information that is required to estimate a Laspeyres index, provided that an estimate of the elasticity of substitution was available. Shapiro and Wilcox [41] actually implemented this idea for the US Consumer Price Index and found that it worked rather well. This is a very significant development, since it shows that it is not impossible to obtain a good approximation to a superlative index using basically the same information set that is presently used to calculate Laspeyres type consumer price indexes.

- In 1988, while discussing Triplett [47], Diewert ${ }^{6}$ suggested that scanner data or detailed computerized firm data on sales would be useful for making estimates of possible substitution biases at the lowest level of aggregation (and perhaps also for estimating new goods bias). The lags in implementing this suggestion were not as long as the above lags - less than 10 years! See Berndt et al. [4], Silver [42], Saglio [40], Reinsdorf [39], Bradley et al. [6], Dal én [11], de Haan and Opperdoes [12] and Hawkes [28] for examples of such scanner data studies.

Given the above examples of rather long lags in the implementation of "new" measurement techniques, it is very likely that at least some of the "new" techniques

\footnotetext{
${ }^{4}$ It took me three years to find a journal that was willing to publish this paper.

${ }^{5}$ See also Boskin et al. [5].

${ }^{6}$ This paper was eventually published in full as Diewert [17]. "Due to the computer revolution, it is now possible to undertake some experiments which could help to determine the extent of the substitution bias. Retail outlets that have computerised price and quantity information on their sales could be sampled. Detailed microeconomic price and quantity vectors $p_{t}$ and $q_{t}$ could be constructed and the Laspeyres, Paasche and Fisher indexes defined by (2)-(4) above could be calculated and compared with corresponding official consumer or producer price indexes that covered the same range of goods. Such firm oriented experiments could provide useful information on the size of the substitution bias." Diewert [17, p. 59] "Numerical computation of alternative methods based on detailed firm data on individual prices and quantities where new goods are carefully distinguished would cast light on the size of the new goods bias. Thus the firm oriented experiments suggested at the end of the previous section to cast light on the size of the substitution bias could also be used to study the size of the new goods bias." Diewert [17, p. 63].
} 
that will be introduced into statistical agency practice over the next twenty years are actually out there right now. Thus in the sections below, we will speculate on what "new" ideas are likely to be implemented by statistical agencies in the coming two decades. In Section 2, we speculate on what are the likely main innovations that statistical agencies will introduce. In Sections 3 and 4, we look at what theoretical developments in consumer and producer price statistics might be introduced. Section 5 concludes with some notes of caution: measurement problems are likely to become more difficult in the coming years in many respects.

\section{The shape of things to come at statistical agencies}

The main changes that are likely to occur at statistical agencies over the next two decades will be centered around data collection techniques. Present methods that rely on the collection of individual price quotes at retail outlets and by mail questionnaires will gradually be replaced by electronic data collection techniques.

- Firms will be asked to submit detailed price and quantity data from their own electronic records via the internet to their statistical agency representative. Firms will also be asked to submit their basic accounting data via the internet. This will be facilitated by the widespread adoption by firms of computer driven accounting packages like Simply Accounting or Quicken for small firms and by customized accounting packages for large firms. This is the one big survey model of data collection from firms that is being pioneered by Statistics Canada. This method of business data collection will lead to a vast improvement in the quality of the production accounts because price, quantity and value data will match up or be consistent for each firm across all categories of output and input. In contrast, the present piecemeal survey method of putting together production accounts is rather haphazard: one survey might collect information on (a few) output prices, another survey collects information on (a few) input prices, yet another survey collects information on values and so on. Putting together this scattered information is like putting together a jigsaw puzzle with most of the pieces missing.

- It is possible that a similar revolution in household data collection could also occur as money for household transactions is replaced by credit and debit card transactions. This switch to plastic away from money opens up the possibility of collecting detailed price and quantity data on individual households electronically rather than by the old diary and recall methods. If this comes to pass, again as in the producer case, there will be a vast improvement in the quality of household data. I am less certain that this rosy prospect actually will materialize because of concerns about privacy.

- Recent developments associated with the expansion of internet services make it possible to collect some types of price information cheaply over the internet. For example, there are internet sites that collect information on prices for 
autos, standard insurance policies, computers and many other products so that consumers can shop for the lowest prices. Internet auction sites might make it possible to collect information on the prices of used durable consumer and producer goods. This would enable statistical agencies to form more accurate information about economic depreciation rates for these durable goods. Lack of accurate information on these depreciation rates is one of the major weaknesses of the current statistical system.

Another major change that is likely to occur in statistical agency practice is that families of indexes will replace single indexes. Some possible examples are:

- The present single CPI (Consumer Price Index) may be replaced by two indexes: one that is timely (like the present index) and another that would be produced with a lag so that current quantity information could be used (to reduce substitution bias) and quality adjustments could be incorporated. This is a recommendation of the Boskin [5] Commission.

- Multiple CPI's may be calculated that reflect different index number purposes or methodologies. For example, some users may feel that a rental equivalence or user cost approach to major consumer durable goods like housing is more appropriate than a money purchases or acquisitions cost approach. Thus statistical agencies may provide alternative indexes that reflect the two approaches. Similarly, some users may want a CPI that has incorporated hedonic quality adjustments or adjustments for increases in the size of consumer choice sets. On the other hand, other users may regard such adjustments as lacking in objectivity and reproducibility and demand a CPI without such adjustments. Finally, some users may want a price index for the domestic purchases of consumer goods and services while other users may want a price index that reflects domestic sales. Of course, this demand for multiple indexes is already being met by the statistical system: the first index is a traditional household CPI while the second index is part of the system of producer price indexes that is imbedded in the national accounts of each country.

- Two decades ago, R. Turvey [49] sent around an artificial data that had seasonal commodities in it that were not available in every month of the year. He then asked each statistical agency to use their normal seasonal adjustment procedures on this data set and to report the results back to him. Needless to say, he found a disconcerting spread in the resulting answers. This is to be expected since it is difficult or impossible to compare the price of grapes in the present month when they are in season with the price of grapes in another month when they are simply not available. Diewert [21] recently took another look at this very old problem and recommended that statistical agencies should construct at least three families of consumer price indexes to deal with this problem. The first index should be a short term month to month index defined over nonseasonal commodities. This index should be useful for the purpose of monitoring short run inflationary trends in the economy. The second index should be a year over 
year index, where the prices in January are compared to the January prices of a base year, the prices in February are compared to the February prices of a base year, etc. This index should give an accurate measure of year over year inflation, which is free from seasonal influences. The third index should be an annual one, ${ }^{7}$ which compares a moving total of 12 months with 12 base year months. This type of annual index can serve as a substitute for the present classes of seasonally adjusted price indexes that rely on "black box" time series methods for seasonal adjustment. Thus again, there is a demand for a family of indexes rather than a single CPI.

Another major change that is likely to occur in statistical agency practice is that the collection of information on service industry output prices and quantities will finally receive the attention that this sector deserves. The broad outlines of the present statistical system date back to the 1940's and 1950's. During that period, economic activity has shifted tremendously from primary industry and the manufacturing sector to the service sector. However, the collection and organization of data by the statistical system never shifted towards better measurement of service industry outputs and inputs. This gap will surely be filled over the next two decades. ${ }^{8}$

We turn now to a discussion of some of the theoretical developments that are likely to take place with respect to household statistics.

\section{Theoretical innovations and consumer price indexes}

Over the next twenty years, many theoretical innovations in modeling the behavior of households will be incorporated into the design of consumer price indexes. Some likely candidates for incorporation include:

- Implementation of Becker's [2] theory of the allocation of time. In Becker's model of consumer behavior, households combine their time with market goods and services to produce finally demanded "commodities" that yield direct utility. For example, a consumer combines the services of a bed with time to produce "sleep utility". The theory also takes into account the disutility of time spent working on the external market and the disutility of the time spent commuting to work. The advantage in implementing this theory is that it will give a more complete picture of household activities: the time costs spent on each

\footnotetext{
${ }^{7}$ This index can be built up from the second class of year over year indexes.

${ }^{8}$ The recent development of the North American Industry Classification is a major step in the right direction since it has a very detailed classification of service sector industries. Corresponding product codes are now being developed and over the coming two decades, there will be a wealth of new information about service sector outputs and prices.
} 
consumption activity will be valued at some opportunity cost of time and added to cost of purchasing goods and services from the marketplace. ${ }^{9}$

- Implementation of an extended version of Becker's model to cover household market production. Becker's model of consumer behavior is concerned with how the household combines purchases of consumer goods and services with its time to "produce" final "commodities" that are demanded by that household to satisfy wants. However, in recent years, as self employment and contracting out of services have grown, many households are producing goods and services at home that are sold to other users. This home production for market sale is not taken into account in Becker's model and so it needs to be extended. The implications of this extension for the cost of living index are profound. Instead of just collecting information on typical consumer goods and services like food, clothing, housing etc., the extended COL to cover household market production would have to include production type inputs like materials (if a product was being made at home) or office equipment (if a business survice was being provided) and various traditional consumer purchases (like heating fuel, telephone services, transportation, home computers etc.) would have to be allocated between business and personal use. In addition to putting these business intermediate inputs into the scope of the COL, it would be necessary to account for the outputs produced as well.

- Implementation of an extended version of Becker's model to medical economics. Illness, disease and accidents reduce capabilities. For example, if I break my leg, playing tennis or jogging is not feasible. If my vision deteriorates (and I do not get new glasses or have an eye operation), then reading a book or watching television may not be feasible. In the context of Becker's theory of the allocation of time, accident or disease adds extra constraints to the consumer's utility maximization problem and of course, this addition of constraints will reduce welfare. Conversely, certain medical treatments will treat the disease or illness and will remove or lessen these extra constraints, thus adding to consumer welfare. This extension of Becker's theory opens up the possibility of providing welfare based evaluations of the effects of certain medical treatments.

- Many of the problems associated with the existing theory of the cost of living index will be solved. There are many technical and conceptual problems with the existing plutocratic ${ }^{10}$ theory of the cost of living index that will be addressed in the coming decades. Some of these problems include:

\footnotetext{
${ }^{9}$ Pollak and Wachter [37] note that it will be difficult to accurately determine the full price (including its time cost) of each finally demanded "commodity". However, for the purpose of constructing a cost of living index, it is not necessary to construct these full prices: all that is required is information on the household's purchases of market goods and services, an opportunity cost of time (usually an external market wage rate) and information on the household's allocation of time across activities.

${ }^{10}$ This is a term coined by Prais [38]. It refers to the current concept of the consumer price index, which weights households according to their expenditures, so that rich households get more weight in the index than poor households.
} 
(1) Current theories for group cost of living indexes assume that each household in the reference population faces the same price for each commodity. ${ }^{11}$ This is obviously not true.

(2) The existing theories for group cost of living indexes assume that the reference population is the same in the two periods being compared. However, births, deaths and immigration make this assumption untrue.

(3) The theory of the COL index assumes that tastes remain unchanged in the two periods being compared. However, education, experience, the process of getting older and advertising will systematically change tastes over time.

(4) The theory of the COL index assumes that various environmental and or demographic factors are the same in the two periods being compared (or alternatively, that preferences are separable from these environmental variables - an unrealistic assumption). Examples of such environmental or demographic variables are: the weather (it affects fuel consumption for heating and air conditioning and it affects what kinds of leisure activities are undertaken), the presence of a new child in the household, the amount of pollution around the household, the condition of the local transportation infrastructure, etc. For some hints on how these problems could be addressed in the context of COL theory, see Caves et al. [7, p. 1409-1411] and Pollak [36].

- Many of the unresolved problems associated with the use of hedonic regression methods for quality adjustment will be solved. The definitive Handbook of Hedonic Methods has still not been written but it surely will be written over the next two decades.

- Recent developments in modeling choice under uncertainty will be used to construct quantity or volume measures for risky products. Current methods for constructing estimates of the real output of the insurance, gambling and options trading industries are not very satisfactory. It is very likely that the vast theoretical economics literature on modeling choice under risk will be used to construct reasonable output or real quantity measures for these inherently risky products. $^{12}$

We turn now to possible theoretical innovations on the producer side of price and quantity measurement theory.

\section{Theoretical innovations and producer price indexes}

Some of the areas of research in the measurement of prices that will probably work their way into producer price indexes are:

\footnotetext{
${ }^{11}$ See Pollak [33,34] or Diewert [15].

${ }^{12}$ For some hints on how to do this, see Diewert $[18,19]$.
} 
- The theory of price indexes at the lowest level of aggregation will be refined considerably. At present, there is considerable uncertainty with respect to the "right" treatment of price quotes from firms at the lowest level of aggregation. Should we use unit values? How should we treat missing price quotes? ${ }^{13}$ What should be done about seasonal commodities? What is the right index number formula to use at the lowest level of aggregation? ${ }^{14}$ Over the next two decades, surely at least some of these questions will be answered in a more or less definitive manner.

- The user cost of capital will work its way into standard national income accounting. The present system of national income accounting does not recognize interest as a cost of using a durable capital input nor does it recognize any capital gains on the asset as a cost offset; only depreciation is recognized as a cost of using capital. In the coming two decades, I expect that interest less capital gains (or equivalently, real interest) will be added to depreciation as a capital cost item and the user cost of capital will become acceptable to national income accountants. However, many practical problems associated with the construction of user costs will be extensively debated. For example, what depreciation rate should be used in the user cost formula? What interest rate should be used? Should we construct an ex ante user cost where expected capital gains are used or should we construct an ex post user cost where actual capital gains on the durable input are used? Also, should user costs be constructed for land and inventories or just be restricted to reproducible capital stock items (such as structures, machines and equipment) ${ }^{15}$

- Natural resource and environmental accounting will also work its way into standard national income accounting. It makes sense to include the growth of forests and other natural resources as a benefit to national output and resource depletion as a cost. Also, improvements (or deprovements!) in various types of pollution should be regarded as benefits (or costs) in the system of accounts. Of course, the practical problem is to find acceptable ways of valuing these changes in the environment but over the next twenty years, I believe that progress will be made and a consensus system of valuation will emerge.

- The problems involved in constructing transfer prices and a geography based system of accounts will be solved. When multinational firms trade inputs and outputs between their production units in different countries, the problem arises of how to value these internal to the firm international transactions. This is known as the transfer price problem. Unfortunately, there are a number of alternative ways for determining these transfer prices ${ }^{16}$ and so there is a need for a consensus to emerge on how these prices should be calculated. The transfer

\footnotetext{
${ }^{13}$ See Armknecht and Maitland-Smith [1] and Feenstra and Diewert [23] on this topic.

${ }^{14}$ See Dalén [10] and Diewert [20] for material on elementary indexes.

${ }^{15}$ For some discussion of these matters, see Diewert [14], Harper et al. [25]and Hulten [30].

${ }^{16}$ For some example of different conceptual frameworks, see Diewert [16].
} 
pricing problem also occurs within a country when we attempt to construct a consistent system of geography based regional accounts: if a national company has regional subsidiaries that trade with each other, then in order to form a system of regional accounts, it is necessary to have agreement on how to calculate these interregional transfer prices. This problem has not received a lot of attention in national income accounting circles but surely it will over the next two decades. Of course, this all ties in with the computer and internet revolution. If each establishment (a business unit with a specific geographical location) is able to report its price and quantity information for an accounting period to the statistical agency and the transfer pricing problem is "solved", then, in principle, it should be easy to aggregate up and form any system of regional accounts that is desired!

- Many difficult accounting problems will be solved. Some examples of difficult accounting problems are: how should one of a kind assets like a movie or a painting be depreciated over time? Should assets be valued at replacement cost or their net realizable value? How should transactions costs or installation costs be treated on the asset accounts? How should goodwill be treated? How should research and development capital be depreciated? What is the proper accounting treatment of stock options? What is the "right" way to do current cost accounting? Surely some of these questions will be answered in the years ahead.

\section{Conclusion}

Although the next two decades will see great progress in measuring price and quantity change more accurately, I believe that in many ways, measurement problems for statistical agencies will become more difficult.

The problem is that the pace of change seems to be accelerating. Why is this a problem? Rates of change for prices and quantities in some domain of definition can only be determined if the same commodities (and the same consumers or producers) are being compared in the two periods under consideration. Accelerating technological progress means that the pace of new product formation is increasing, which in turn means that all of the new goods and services that appear in the present period cannot be readily compared with the old goods and services of the previous period. Large reductions in trade barriers since the end of World War II and reductions in real transport costs have led to a massive increase in international trade and a further proliferation in products that are new to the local marketplace. This in turn has led to the disappearance of many local firms, which of course creates problems for the measurement of real output change. ${ }^{17}$ Conversely, there is a movement towards

\footnotetext{
${ }^{17}$ Ideally, we would want to compute establishment specific rates of output and input growth at the lowest level of aggregation. If an establishment is present in only one of the two periods under consideration, the ideal computation becomes impossible.
} 
increased self employment, ${ }^{18}$ which of course has led to an influx of new firms. In either case, it is difficult to compare like with like.

On the household side of things, it is a similar story of increasing measurement difficulties. Generally lower transport costs and increasing real income have led to a large increase in international tourism. As households purchase an increasing share of their goods and services abroad, it is increasingly difficult to compute a consumer price index. A closely related problem is the growth of internet shopping, which leads to an increasing share of goods being bought abroad. Also, international business consulting is increasing so that consumer workers increasingly purchase their consumer bundles in a variety of countries. Again, this creates difficulties for the accurate construction of a domestic household CPI.

In conclusion, over the next twenty years, statistical agencies will make remarkable improvements to their measurement of basic price and quantity movements but many problems will remain to be solved. Some of these problems will be impossible to solve.

\section{References}

[1] P.A. Armknecht and F. Maitland-Smith, Price Imputation and Other Techniques for Dealing with Missing Observations, Seasonality and Quality Changes in Prices Indices, IMF Working Paper 99/78, Statistics Department, International Monetary Fund, Washington, DC, 1999.

[2] G.S. Becker, A Theory of the Allocation of Time, The Economic Journal 75 (1965), 493-517.

[3] E.R. Berndt, The Practice of Econometrics, Classic and Contemporary, Addison-Wesley Publishing Co., Reading, MA, 1991.

[4] E.R. Berndt, Z. Griliches and J.G. Rosett, Auditing the Producer Price Index: Micro Evidence from Prescription Pharmaceutical Preparations, Journal of Business and Economic Statistics 11 (1993), 251-264.

[5] M.J. Boskin, E. Dulberger, R. Gordon, Z. Griliches and D. Jorgenson, Toward a More Accurate Measure of the Cost of Living, Final Report to the US Finance Committee, Government Printing Office, Washington, DC, 1996.

[6] R. Bradley, B. Cook, S.E. Leaver and B.R. Moulton, An Overview of Research on Potential Uses of Scanner Data in the US CPI, in: Proceedings of the Third Meeting of the International Working Group on Price Indices, B. Balk (ed.), Statistics Netherlands, Voorburg, April 16-18, 1997, pp. 169-181.

[7] D.W. Caves, L.R. Christensen and W.E. Diewert, The Economic Theory of Index Numbers and the Measurement of Input, Output and Productivity, Econometrica 50 (1982), 1393-1414.

[8] R. Cole, Y.C. Chen, J.A. Barquin-Stolleman, E. Dulberger, N. Helvacian and J.H. Hodge, QualityAdjusted Price Indexes for Computer Processors and Selected Peripheral Equipment, Survey of Current Business 66(1) (1986), 41-50.

[9] A.T. Court, Hedonic Price Indexes with Automotive Examples, in: The Dynamics of Automobile Demand, General Motors Corporation, New York, 1939, pp. 99-117.

[10] J. Dalén, Computing Elementary Aggregates in the Swedish Consumer Price Index, Journal of Official Statistics 8 (1992), 129-147.

\footnotetext{
${ }^{18}$ Whether this is driven by the tax system, which generally favours self employment, or the contracting out phenomenon or the new internet technology, remains unknown. All we know is that in most OECD countries, the proportion of self employed workers has been increasing in recent years.
} 
[11] J. Dalén, Experiments with Swedish Scanner Data, in: Proceedings of the Third Meeting of the International Working Group on Price Indices, B. Balk, ed., Statistics Netherlands, Voorburg, April 16-18, 1997, pp. 163-168.

[12] J. De Haan and E. Opperdoes, Estimation of the Coffee Price Index Using Scanner Data, in: Proceedings of the Third Meeting of the International Working Group on Price Indices, B. Balk, ed., Statistics Netherlands, Voorburg, April 16-18, 1997, pp. 183-201.

[13] W.E. Diewert, Exact and Superlative Index Numbers, Journal of Econometrics 4 (1976), 115-146; reprinted as in: Essays in Index Number Theory, (Vol. 1), W.E. Diewert and A.O. Nakamura, eds, North-Holland, Amsterdam, 1993, pp. 223-252.

[14] W.E. Diewert, Aggregation Problems in the Measurement of Capital, in: The Measurement of Capital, D. Usher, ed., University of Chicago Press, Chicago, 1980, pp. 433-528.

[15] W.E. Diewert, The Theory of the Cost of Living Index and the Measurement of Welfare Change, pp. 163-233 in: Price Level Measurement, W.E. Diewert and C. Montmarquette, eds, Statistics Canada, Ottawa, 1983, pp. 163-233, reprinted as in: Price Level Measurement, W.E. Diewert, ed., North-Holland, Amsterdam, 1990, pp. 79-147.

[16] W.E. Diewert, Transfer Pricing and Economic Efficiency, in: Multinationals and Transfer Pricing, A.M. Rugman and L. Eden, eds, Croom Helm, London, 1985, pp. 47-81.

[17] W.E. Diewert, The Early History of Price Index Research, in: Essays in Index Number Theory, (Vol. 1), W.E. Diewert and A.O. Nakamura, eds, North-Holland, Amsterdam, 1993, pp. 33-65.

[18] W.E. Diewert, Symmetric Means and Choice Under Uncertainty, in: Essays in Index Number Theory, (Vol. 1), W.E. Diewert and A.O. Nakamura, eds, North-Holland, Amsterdam, 1993, pp. 355433.

[19] W.E. Diewert, Functional Form Problems in Modeling Insurance and Gambling, The Geneva Papers on Risk and Insurance Theory 20 (1995), 135-150.

[20] W.E. Diewert, Axiomatic and Economic Approaches to Elementary Price Indexes, Discussion Paper 95-01, Department of Economics, University of British Columbia, Vancouver, Canada, January 1995.

[21] W.E. Diewert, Index Number Approaches to Seasonal Adjustment, Macroeconomic Dynamics 3 (1999), 48-68.

[22] E. Dulberger, The Application of a Hedonic Model to a Quality Adjusted Price Index for Computer Processors, in: Technology and Capital Formation, D.W. Jorgenson and R. Landau, eds, MIT Press, Cambridge, MA, 1989, pp. 37-75.

[23] R.C. Feenstra and W.E. Diewert, Imputation and Price Indexes: Theory and Evidence from the International Price Program, Discussion Paper, Department of Economics, University of British Columbia, Vancouver, Canada, V6T 1Z1, April 1961.

[24] Z. Griliches, Hedonic Price Indexes for Automobiles: An Econometric Analysis of Quality Change, in: The Price Statistics of the Federal Government, G. Stigler, (Chairman), NBER, Columbia University Press, New York, 1989, pp. 137-196.

[25] M.J. Harper, E.R. Berndt and D.O. Wood, Rates of Return and Capital Aggregation Using Alternative Rental Prices, in: Technology and Capital Formation, D.W. Jorgenson and R. Landau, eds, The MIT Press, Cambridge, MA, 1997, pp. 331-372.

[26] J.A. Hausman, Valuation of New Goods under Perfect and Imperfect Competition, in: The Economics of New Goods, T.F. Bresnahan and R.J. Gordon, eds, University of Chicago Press, Chicago, 1999, pp. 209-237.

[27] J.A. Hausman, Cellular Telephone, New Products and the CPI, Journal of Business and Economic Statistics 17 (1998), 1-7.

[28] W.J. Hawkes, Reconciliation of Consumer Price Index Trends in Average Prices for QuasiHomogeneous Goods Using Scanning Data, in: Proceedings of the Third Meeting of the International Working Group on Price Indices, B. Balk, ed., Statistics Netherlands, Voorburg, April 16-18, 1997, pp. 145-161.

[29] J.R. Hicks, The Valuation of the Social Income, Economica 7 (1990), 105-140.

[30] C.R. Hulten, The Measurement of Capital, in: Fifty Years of Economic Measurement, E.R. Berndt and J.D. Triplett, eds, the University of Chicago Press, Chicago, 1975, pp. 119-158. 
[31] P.J. Lloyd, Substitution Effects and Biases in Nontrue Price Indices, American Economic Review 65 (1996), 301-313.

[32] B.R. Moulton, Constant Elasticity Cost-of-Living Index in Share Relative Form, Bureau of Labor Statistics, Washington DC, December 1980.

[33] R.A. Pollak, Group Cost-of-Living Indexes, American Economic Review 70 (1980), 273-278.

[34] R.A. Pollak, The Social Cost-of-Living Index, Journal of Public Economics 15 (1981), 311-336.

[35] R.A. Pollak, The Theory of the Cost-of-Living Index, in: Price Level Measurement, W.E. Diewert and C. Montmarquette, eds, Statistics Canada, Ottawa, 1983, pp. 87-161; reprinted as in: The Theory of the Cost-of-Living Index, R.A. Pollak, eds, Oxford University Press, Oxford, 1989, pp. 3-52; also reprinted as in: Price Level Measurement, W.E. Diewert, ed., North-Holland, Amsterdam, 1990, pp. 5-77.

[36] R.A. Pollak, The Treatment of the Environment in the Cost-of-Living Index, in: The Theory of the Cost-of-Living Index, R.A. Pollak, ed., Oxford University Press, Oxford, 1989, pp. 181-185.

[37] R.A. Pollak and M.L. Wachter, The relevance of the household production function and its implications for the allocation of time, Journal of Political Economy 83 (1975), 255-277.

[38] S.J. Prais, Whose Cost of Living? The Review of Economic Studies 26 (1959), 126-134.

[39] M. Reinsdorf, Constructing Basic Component Indexes for the US CPI from Scanner Data: A Test Using Data on Coffee, BLS Working Paper 277, Bureau of Labor Statistics, Washington, DC, 1996.

[40] A. Saglio, 1995, Comparative Changes in Average Price and a Price Index: Two Case Studies, in: Proceedings of the First Meeting of the International Working Group on Price Indices, L.M. Ducharme, ed., Statistics Canada, Ottawa, October 31-November 2, 1994.

[41] M.D. Shapiro and D.W. Wilcox, Alternative Strategies for Aggregating Prices in the CPI, Federal Reserve Bank of St. Louis Review 79(3) (1997), 113-125.

[42] M. Silver, Elementary Aggregates, Micro Indices and Scanner Data: Some Issues in the Compilation of Consumer Price Indices, Review of Income and Wealth 41 (1995), 427-438.

[43] M. Silver, An Evaluation of the Use of Hedonic Regressions for Basic Components of Consumer Price Indices, The Review of Income and Wealth 45(1) (1999), 41-56.

[44] G. Stigler, (Chairman), The Price Statistics of the Federal Government, NBER, Columbia University Press, New York, 1961.

[45] J.E. Triplett, The Economic Interpretation of Hedonic Methods, Survey of Current Business 66(1) (1986), 36-40.

[46] J.E. Triplett, Hedonic Functions and Hedonic Indexes, in: The New Palgrave: A Dictionary of Economics, (Vol. 2), J. Eatwell, M. Milgate and P. Newman, eds, The Macmillan Press, London, 1987, pp. 630-634.

[47] J.E. Triplett, Price and Technological Change in a Capital Good: A Survey of Research on Computers, in: Technology and Capital Formation, D.W. Jorgenson and R. Landau, eds, MIT Press, Cambridge, MA, 1989, pp. 127-213.

[48] J.E. Triplett, Economic Theory and BEA's Alternative Quantity and Price, Survey of Current Business 72(4) (1992), 49-52.

[49] R. Turvey, The Treatment of Seasonal Items in Consumer Price Indexes, Bulletin of Labour Statistics 4th Quarter, International Labour Office, Geneva, 1979, pp. 13-33.

[50] F.W. Waugh, Quality Factors Influencing Vegetable Prices, Journal of Farm Economics 10(2) (1928), 185-196.

[51] A.H. Young, Alternative Measures of Change in Real Output and Prices, Survey of Current Business 72 (April 1992), 32-48. 
Comments by Brent R. Moulton

National Income, Expenditure and Wealth Accounts, Bureau of Economic Analysis, US Department of Commerce, Washington, DC, USA

I recognize that our topic this afternoon is the next twenty years, but first I would like to reflect briefly on the remarkable advances that have been made in price measurement during the last ten years.

Ten years ago, I think it's fair to say that the drop-off in inflation during the 1980s had led to an environment in which relatively little attention was being given to price measurement issues, either by the policy makers or by the academic community. Some improvements were being made - note the adoption of the hedonic-adjusted computer price indexes by BEA in 1986, BLS's multifactor productivity program, and research on superlative indexes. But I also recall an environment in which Michael Boskin's initiative to upgrade our economic statistics failed to garner the necessary political support.

Let's review some highlights of the last decade:

- Robert Gordon's 1990 book, The Measurement of Durable Goods Prices, systematically critiqued official price indexes and estimated alternative indexes.

- The Conference on Research in Income and Wealth (CRIW) held several important conferences on price-related topics, later published as Output Measurement in the Service Sector, Price Measurements and Their Uses, and The Economics of New Goods.

- Marshall Reinsdorf's seminal paper on outlet substitution pointed to measurement problems that previously had gone unnoticed and ultimately led to an entire research agenda on the intricacies of price index estimation.

- BLS published a series of papers in the December 1993 Monthly Labor Review, thereby beginning to develop estimates of the size of various CPI biases.

- Zvi Griliches, in his AEA presidential address, issued a call to the profession to give more attention to economic data. With several co-authors, he studied pharmaceutical prices and price indexes.

- The BLS producer price index program began aggressively expanding its coverage of services.

- BEA switched to chain-type quantity and price measures using a Fisher formula for measuring changes in real GDP and other aggregates.

- The Senate Finance Committee held a series of hearings on CPI bias, then appointed an advisory commission chaired by Michael Boskin. The final report of the commission educated the economics profession as well as the public and resulted in unprecedented attention being given to economic measurement.

- The BLS took a number of steps to address CPI biases, including formula bias, adoption of the geometric mean for lower level estimation, more frequent weight updates, expanded use of hedonics, and development of new historically consistent and superlative-type indexes. 
At the end of this decade, I see price and quantity measurement as having moved back to center stage in the profession's research agenda. Rather than being seen as an arcane area for specialists and government agencies, the importance of measurement has now been imprinted on the consciousness of the economics profession.

Turning to the next twenty years (or perhaps more modestly, the next five to ten years), what do I see as the research agenda? My answer to that question is probably somewhat different now, after spending the last year and a half working on the national accounts, than it would have been before.

The biases addressed in the Boskin report obviously remain central to our research agenda. While considerable progress has been made toward dealing with upperand lower-level substitution bias, the problems of quality, new-goods, and outletsubstitution bias remain as difficult, unsolved problems.

I'd like to focus on some specific areas for which improvement is needed:

- With the release of the comprehensive revision of the NIPA's (National Income and Product Accounts) scheduled for this October, software will be treated as fixed investment. Along with this change, BEA plans to introduce software price indexes that are, in part, quality adjusted using hedonic methods. We find that the hedonic quality adjustment is important. The price indexes based on hedonic quality adjustment tend to show significant price declines, whereas matched-model indexes (such as the software PPI) tend to show little price change. Software investment will be large as a share of total fixed investment, and it will be important to take account of quality improvements.

- The service sector is a perennial problem. Better measures of price and output of bank services, insurance, and other hard-to-measure services are very high on our agenda. Improving our measures of these sectors will require cooperation among the statistical agencies as well as between the statistical agencies and the academic community.

- There is a lack of good price data for construction, especially non-residential construction. The recent Gullickson-Harper study of problem industries, as identified by long-run negative trends in multifactor productivity, drew attention to construction, as well as banking and insurance.

- Measurement of medical care services has received a lot more attention recently, and was the topic of a recent CRIW conference. BLS is to be congratulated for developing PPI's that track a course of treatment instead of inputs. Nevertheless, much work remains in the area of quality adjustment.

- Technology change in capital goods other than computers has not received sufficient attention. Communications equipment, instruments, photocopy and related equipment, and machine tools are examples of capital equipment that have recently had large improvements in quality that may not fully be reflected in the PPI's. I would particularly highlight telecommunications equipment, which is rapidly growing and if correctly quality adjusted, might rival computers in importance. 
Besides pointing to industries and commodities that need to receive more attention, I'd also like to make a couple of modest suggestions on specific research topics that may have a large payoff:

- National accountants make heavy use of the idea of benchmarking; that is, finding data and methodologies that ensure the internal consistency of the data and guard against data series permanently drifting off course. Price indexes, however, are only rarely benchmarked. One way of interpreting Marshall Reinsdorf's influential 1993 outlet-substitution paper is that he came up with a way of benchmarking certain CPI series by comparing trends in price indexes to trends in average prices for goods for which quality change was relatively unimportant. My own opinion is that this approach could, and should, be applied more widely. BLS could produce a number of additional average price series for items like rent and certain apparel items. Even in cases for which quality change is going on, it would be useful to know more about the relationship between average prices and price indexes.

- In constructing price indexes, I hypothesize that there may be an important interaction between quality adjustment and sample replacement. The sample replacement strategy of linking together the old and new samples is implicitly based on the assumption that the two samples are both representative at the time of replacement - an assumption that, if true, would appear to imply that sample replacement is unnecessary. If the average quality-adjusted price of an outof-date sample is systematically different from the current population qualityadjusted price, then it would be appropriate to make a quality adjustment as part of the sample replacement procedure. A paper presented at last year's meeting of the Ottawa group by Tim LaFleur, Karin Moses, and myself included some empirical evidence in the case of televisions that important quality improvements may not be fully accounted for because quality changes are linked out during periodic sample replacements.

- I recommend additional research on disappearing varieties and the treatment of their replacements in price index construction. Although I think the paper that Karin Moses and I wrote for the 1997 Brookings Papers probably was probably misinterpreted in the context of the debate that was then going on about the Boskin report, it does present compelling evidence that the replacement of old versions of an item with new versions is critical to measuring changes in both price and quality.

- Finally, I'll mention computer prices. While I think this is one of the success stories for the US statistical system, it is also important to recognize that real growth in computers is now one of the most important contributors to GDP growth. In view of its importance, I think it would be very worthwhile to carefully critique and monitor the hedonics-based indexes to ensure that the quality adjustments result in indexes that neither understate nor overstate the dramatic price declines that have occurred. 
Comments by Jack E. Triplett

Brookings Institution, Washington, DC, USSA

Members of the panel were invited to discuss improvements in the US Consumer Price Index (CPI) and to suggest an agenda of research issues in price measurement for the future.

\section{Improvements}

\subsection{COL index framework}

Controversy has broken out anew on an old issue: Does the concept of the cost of living (COL) index provide the underlying conceptual framework for the CPI?

The United States is one of a small number of countries (which also includes the Netherlands and Sweden) that accept the COL index framework. Most countries' statistical agencies do not. The Boskin Commission report stated unequivocally that the US CPI should be interpreted as an approximation to a COL index. I agree. But a no doubt unintended side effect of the report was to heighten an international dispute on this matter, a dispute in which the US position - shared by the BLS and the CPI's critics - is decidedly in the minority.

Incidentally, the Bureau of Labor Statistics (BLS) endorsement of the COL index is not a recent matter. It dates to the 1970's when Joel Popkin, Robert Gillingham, and I were all in the BLS Office of Prices and advocated the COL index framework, and to the 1978 CPI revision that was managed by John Layng, who was also an advocate of the COL framework for the CPI. In the intervening 20 years, I have never heard of anyone in a responsible position among the BLS staff who opposed the COL position, some rather sloppy and ambivalent writing for BLS publications notwithstanding. The Boskin Commission's endorsement of a COL concept was not something that BLS staff, present or in the past 20 years, opposed. It is important to emphasize that point because there has been substantial confusion on the matter in the public discussion of the Boskin Commission report and its recommendations.

The international dispute about the COL framework has become important because there is a tremendous push for international comparability of economic statistics. Alan Greenspan, in a recent speech in Europe, called for more international comparability of CPIs, essentially in the pursuit of international harmonization of monetary policies. For very different reasons, the preparation of a new international manual for CPIs, which would be comparable to the huge international manual for construction of national accounts [4], is just getting underway.

Significantly, a set of internationally comparable CPIs exists now, in the European Harmonized Indexes of Consumer Prices (HICP), which are mandatory for all the countries in the European Union, and will probably in the future be followed as well by a set of associated countries and candidate countries, some 29 countries in all. 
Additionally, Eurostat (the European statistical agency) has proselytized among countries of Central and South America, proposing that they adopt the Eurostat HICP framework for their indexes, in particular, for the harmonized CPIs that are now being constructed for the Mercosur countries (Argentina, Brazil, Paraguay, Uruguay), with Chile and Bolivia as associated participants. It does not take much foresight to see that the US may soon be surrounded by world CPIs that take quite different approaches from the COL oriented approach of the BLS.

These HICP indexes are emphatically not COL index oriented. They follow the intellectual parentage of Hill [11], who contends that a COL index is not appropriate as a price index for measuring inflation. The HICP indexes do not subscribe to a flow of services approach to measuring owner-occupied housing, and under a no imputations rule, they will not use the rental equivalence approach for measuring owner-occupied housing that was adopted in the US CPI in 1983. Indeed, one possible HICP measure of owner-occupied housing will resemble the old BLS approach, abandoned (for good reason) in 1983.

The idea that the CPI should approximate a COL index is not without controversy in the United States. For example, Angus Deaton has written [15]: "The Boskin Commission's ... recommendation that the Bureau of Labor Statistics should establish a cost of living index as its objective in measuring consumer prices, taken by them as essentially obvious, is a contentious proposition that requires serious argument. In fact it is unclear that a quality-corrected cost of living index in a world with many heterogeneous agents is an operational concept."

If there is not agreement that the COL index provides the underlying conceptual framework for the CPI, then we have no way to determine whether changes to the $\mathrm{CPI}$ are improvements, and no way to determine what improvements to the CPI are needed. So my first point is that -although it is neither research nor CPI improvement, strictly speaking - we need more international consensus on what a COL index means in practical application, and more enlightenment about what alternative conceptual frameworks imply. I am at work on a contribution to that topic myself [subsequently circulated as Should the Cost of Living Index Provide the Conceptual Framework for a Consumer Price Index? presented at the Measurement of Inflation International Conference, Cardiff University, September 1999].

\subsection{Escalation uses}

The issues surrounding the COL index have become more muddled by the fact that the Boskin report was commissioned, not out of a pure concern for inflation measurement, as was the NBER's Stigler Committee report of 1961, but out of concern over escalation of social security payments. There is a difference between inflation measurement, on the one hand, and on the other, the principles that determine how we want social security incomes to behave. In this matter, I heartily endorse Zvi Griliches' Congressional testimony and his remarks in other places, which I might paraphrase as follows. 
Suppose granny now has access to a VCR with a remote that lets her channel surf without causing misery to her aching hip, or that she now has access to hip replacement surgery that (in this context) substitutes for the VCR. Whether one wants to reduce granny's social security payments because of such improvements is a wholly different question from whether quality adjustments for them should be made in her COL index.

Quality adjustments for improved electronics and improved medical procedures are necessary because the COL index holds granny's standard of living constant. Escalation issues, on the other hand, concern partly whether we want granny to be able to improve her living standard, to consume at the higher level that improvements in technology permit.

Part of the issue here is the definition of income or wealth that is being deflated with the COL index, a point that I made many years ago [17]. But a more important part concerns equity in sharing the fruits of technological change that increases average living standards. It is not so surprising that noneconomists get escalation issues tangled up with price measurement issues, but it is a bit more distressing when economists do likewise.

Improving the CPI, therefore, requires more attention to the principles for equity in escalation policy and to income measurement issues for escalation. Otherwise, mistaken proposals for improving the CPI will undoubtedly emerge from concerns that are, at their root, questions about fairness in the distribution of incomes between different social groups. Both inflation measurement and escalation issues are important - it is just that we should avoid tangling one issue with the other.

\subsection{Statistical and sampling techniques}

Statistical issues in the CPI need far more attention. In contrast to the Stigler Committee report, the Boskin Commission report said nothing substantive about statistical matters. No other country does probability sampling of outlets and items or uses a household point of purchase survey in conjunction with a household consumption survey as the US does. If you press them on it, most will say, first, that they cannot afford it and, second, that they do not think that probability sampling would make much difference anyway.

The BLS approach has been in place for twenty years. To my knowledge, it has never had a comprehensive statistical review, which is long overdue. I am not fully convinced that the BLS statistical apparatus is necessarily the best way to go, or the only way to go, but I lack the statistical competence to say very much about it.

For example, the Australians, who do not use probability sampling, subdivide their CPI into some 1,500 different components, which they justify largely on the grounds that they want CPI components to be as homogeneous as possible with respect to price behavior. Sample sizes get very small under the Australian procedure, so one gets apprehensive about the representativeness and the statistical properties of the samples. The BLS probability sampling route requires, by its nature, much broader 
CPI aggregates. The BLS avoids the representativeness problems that may arise in the Australian index, but the BLS approach invites the kinds of statistical problems that arise out of the extreme heterogeneity in a large number of the CPI's 207 basic components.

Intuitively, I have reservations about both the Australian judgmental and the BLS probability approach, but I have never seen an analysis presenting the statistical tradeoffs between them, and reviewing whether some midway position exists that might be as good at lower cost or perhaps better at the same cost.

\subsection{Consumer expenditure survey}

It is time to improve the BLS consumer expenditure survey (CEX). The CEX provides the weights for the CPI. It should be obvious that one cannot have an accurate CPI without having accurate weights.

One cannot, as well, estimate the substitution bias in a fixed-weight index without having accurate weights. For example, most recent estimates of the bias in a Laspeyres index number do it by comparing the Laspeyres index to a superlative index number, such as the Fisher index (which is the geometric average of Laspeyres and Paasche indexes). How much of the difference between these two indexes is statistical noise arising out of inaccurately estimated weights?

The CEX is far too small. I applaud the BLS decision to increase it by 50 percent, but that still is only 7,500 households, and that is a small survey. Many countries have larger surveys, although they often support them by collecting less detailed information. We need a CEX that is substantially larger than the survey's present size.

Additionally, other CEX problems need attention. For example, the within-sample attrition rate is a cause for concern, and there is also a need to examine the obtrusiveness of the survey instrument to determine if it has something to do with the rapid falloff in responses as the survey's panel extends. This, again, is a set of issues that affects the accuracy of the CPI, and it is a set of issues on which CEX users and CEX staff have largely been in agreement over many years. Some coordinated, crossgovernment action needs to be initiated. The BLS is the natural place, in the absence of any centralized statistical decision-making in the US, to look for leadership on CEX issues.

\section{The research agenda}

\subsection{Substitution bias}

The Boskin Commission estimated the total bias in the CPI at 1.1 index points; only 0.1 of that was what it called upper-level substitution bias. Thus, bias within the components outweighs between-component substitution bias by a ratio of 10 to 
1. Interestingly, substitution bias estimates for other countries that have a greater number of basic components than the 207 in the US CPI show roughly the same amount of upper-level substitution bias.

I conclude from the 10 to 1 relative sizes of substitution bias and non-substitution bias estimates that substitution bias between CPI basic components - for the past 65 years the dominant issue in the price index number literature - is dead as a research issue. So long as the CPI weights are kept up to date and are changed frequently, substitution bias among the components for which the weights are fixed is small enough to be neglected. Although I raised some controversy a dozen years ago with the phrase all the fruit has been picked from that tree, professional opinion now concurs.

Future price index research should therefore focus on measuring CPI components. It is at the component level, measuring the prices of cars and computers and - yes bananas, where the problems lie. The Boskin Commission's focus on component price indexes, on new products and quality change, was right on the mark.

\subsection{Lower level price aggregation}

How one aggregates the CPI's 207 basic components into the overall CPI may be a dead issue, but the question of how one aggregates the individual price quotations into a price index for cars or for bananas is certainly not resolved. I want to raise some serious reservations about what the Boskin Commission called lowerlevel substitution bias within CPI components. Faced with evidence that geometric means of price relatives showed lower rates of inflation than arithmetic means of price relatives, the Boskin Commission decided that this looked like the difference between a Laspeyres index (arithmetic mean) and a Cobb-Douglas index (geometric mean), and that therefore the geometric mean-arithmetic mean issue was just another form of substitution bias (between red delicious and yellow delicious apples, as it put it).

This interpretation is questionable. Perhaps the consumer behavior that is relevant to the price index for apples is nothing more than the same long-term commodity substitution that has so long dominated the price index literature - substitution between, say, apples and bananas, as the price of the latter has fallen relative to the former. But I doubt it.

In the long run, I may substitute more bananas for apples, as the relative price of bananas falls. This is classic commodity substitution, which leads to substitution bias in the aggregate fixed-weight Laspeyres CPI. But in the short run, I may exercise my taste for variety in diet by buying bananas when they are on sale, rather than when they are not, or I might (but don't) go across the street where they are on sale in preference to buying from the store where they are not on sale. This is consumer shopping and search behavior, not commodity substitution behavior. For food commodities that are more durable than bananas, I might choose to stock up and to rebuild my inventory of consumption goods when they are on sale, and buy at nonsale prices only when I have 
made an inventory error or confront unforeseen circumstances. Consumer inventory behavior probably does not resemble the behavior that is modeled as commodity substitution. The correct formula for lower-level indexes - the price index for bananas - cannot be determined solely by the principles of commodity substitution that guide the choice of upper-level CPI formulas.

Thus, as Pollak [15] contends, consumer behavior that matters within the price index for bananas (bananas are, after all, in the United States, as close to a homogeneous commodity as one can find) is not consumer commodity-substitution behavior, but consumer search, shopping, inventory, and related behaviors. We need much more research into the nature of the index number problem that the Commission discussed under the lower-level substitution bias name, research that will explain how consumer search and shopping behaviors should be built into a COL index, and therefore how the BLS should compute the price index for bananas. The Boskin Commission (and the BLS, as well) did us a disservice by making this lower-level aggregation problem appear to be a simple and conventional problem, when it is in fact a complex one on which little is known.

Having said this, I should make clear that I am not opposed to the BLS' recent move to a geometric mean for the CPI as an interim step, nor am I asserting that there is no commodity substitution in any of the 207 item indexes for the CPI (some of which are quite heterogeneous). It is, rather, that the problem to be solved is a more complex problem than the one that the term lower level substitution suggests.

\subsection{Quality change}

Quality change was a major concern of the Stigler Committee and of the Boskin Commission 25 years later. It undoubtedly will still be on the agenda 20 years from now.

A recently-developed distinction (that is not yet very clear) is between quality change in the universe and quality change in the CPI sample. Almost the entire history of research on quality change has concerned the questions: What happens when there is quality change among the goods that are included in the CPI sample? And, do the methods used by the BLS create bias in the index?

Despite some recent assertions that this within-sample quality change issue is irrelevant (that seems to be the interpretation of [8]), quality change within the sample remains an important question. Moreover, it still remains true that the implications of methods actually used to control for quality change within the sample are widely misunderstood. When quality is improving, the bias from the most widely employed quality adjustment method (in [18], I called it deletion, but this might not be good terminology) is downward when prices are rising and upward when prices are falling. It is not in general true that the direction of the bias in the index depends on the direction of quality change; it is more nearly the case that it depends on the direction of the true price change. 
On useful research on quality change within the CPI sample, I would like to repeat a proposal that I made at the NBER meeting on the CPI that Zvi Griliches organized in April, 1995. I would like to see BLS conduct statistical audits on the treatment of quality changes in the CPI. These should be carried out on a sample of commodities and services, taking care to select a sample that contains not only commodities for which quality change is thought to be rapid, but also some others where it is not so evident. William Nordhaus [14] has now proposed the same thing, so I join forces with him.

Price index research outside government tends to be biased toward those goods and services where researchers think rapid quality change has occurred. A doctoral student who wanted to study price indexes for computers or for banking or for medical care will, understandably, get a far different reception from his advisor than the student who proposes research on price indexes for hair brushes or for hair cuts. Research ought to be directed, to be sure, where the payoff is likely. But an estimate of the bias in the aggregate CPI will itself be biased if based on existing research, because the research topics are not randomly selected with respect to the components of the CPI. Thus, the BLS should conduct a representative series of audits, taking care to cover components in which there has been rapid technological change and components in which there has been little.

The Boskin Commission stated that its extrapolation of research studies to areas of the index in which no research had been done was justifiable because an estimate of zero bias is itself biased. What the commission apparently had in mind was a world in which the sign of the quality change bias is known, and that it is always upward. That is a serious misreading of research. Studies that have shown downward bias in CPI components at various times include rent, automobiles, and clothing, to name some items with major weight. If the unknown bias also has an unknown sign, an estimate of zero for items that have not been studied is not such a bad one.

We need better estimates of the effect of CPI quality adjustment procedures. A CPI audit program would be very helpful. Only BLS can carry out such a research project. The project should of course bring in external data as well as carrying out a careful examination of the quality changes that are encountered within the CPI sample. Moulton and Moses [13] is an excellent place to start on developing data on quality changes that are conducted within the CPI sample. My old paper with McDonald [16] was a kind of audit, on an actual BLS price index (it was from the PPI, not the CPI). Another example is Berndt et al. [1] on drug prices. This is a very small literature that needs to be expanded.

Recently, another problem has come to the fore. Rapid quality change may mean that price change is more likely to occur on newly introduced, improved products that might be outside the CPI sample. For example, a new computer enters the market at a lower quality adjusted price than the old ones. Even if the new computer is put into the CPI market basket immediately (which is in fact seldom the case because of sampling and other considerations), the price change that occurs when the product enters will be missed, unless the prices of the computers that are included in the CPI 
sample fall to meet the quality/price ratio of the newly introduced computer. This scenario might have been implicit in what was discussed in years past, but making it explicit clarifies some of the issues. This implies some research on the ways that quality change and new product varieties enter the market, their effects on the price behavior of old varieties, and the extent that new varieties push old ones out of the market, without necessarily producing price/quality equilibrium among new and old product prices.

\subsection{New products}

Another major research agenda item is the new product, consumer surplus problem, as discussed by Hausman [10] and the Boskin Commission. This is clearly a long-run research agenda item. Although one might hope that hedonic methods offer hope for ameliorating the quality change problem in consumer price indexes, estimation of consumer surplus and the effects of new products lack at this writing an effective, practical method for implementation in the CPI.

There is a useful parallel between the Stigler Committee's discussion of substitution bias and the Boskin Commission's discussion of consumer surplus. Looking back at the Stigler Committee's 1961 proposal to estimate substitution bias, it is remarkable how deficient was 1961 methodology for carrying out that suggestion. Only in the 1970 's did computer capacity finally exist to permit estimation of substitution effects econometrically. Even then (as we soon found out when in the early 1970's we began the BLS project to estimate the substitution bias in the CPI), there were huge problems that were not tractable with the consumer demand systems, the econometric methodologies, and the computer capacities that existed at that time.

The solution to the commodity substitution problem really came with Erwin Diewert's [6] remarkable demonstration that one could approximate the substitution bias very closely with an extremely simple and easy to carry out calculation of a superlative index number. As a result of both BLS econometric estimates (such as [2,12]) and the superlative index number approaches, we now have considerable confidence in that $0.1-0.2$ substitution bias estimate cited by the Boskin Commission. In contrast, before any of this work was done, it was quite common for economists to guesstimate far higher substitution biases in the CPI (perhaps three or more percentage points annually).

The Boskin Commission guesstimated the effect of new products (and quality change), in the absence of firm empirical estimates. Although research of the type pioneered by Hausman [10] will be valuable, it is hardly conceivable that we will accumulate very rapidly studies on a very high proportion of new products that are introduced. And the substantial difficulties exposed by Bresnahan [3] suggest that prospects are remote for an aggregate empirical estimate along the lines that Hausman pioneered.

Thus, I suspect that we will not make that much headway on the new product issue until someone produces a practical innovation for estimating reservation prices and 
consumer surplus comparable to the one that Diewert introduced for estimating the substitution bias. That is another way of saying that measurement improvements in the CPI may require the search for simpler procedures rather than more complex ones.

\subsection{Services}

Another topic is measuring the prices of services. Surely, this is a question that has waited for a long time. The book by Griliches [9] reminds us not only of the long period that passed since the earlier flurry of interest provoked by Fuchs [7], but also the lack of progress over that interval. Although Barry Bosworth and I have a substantial project at the Brookings Institution on improving the measurement of output and productivity in the service sector, as well as money to fund projects, I must report that it has been extremely difficult to find researchers who want to commit to the task. Throwing money at the problem doesn't help if the problem does not attract good minds. I hope that twenty years from today we are not still saying that meaningful research needs to be done on the concepts of prices and outputs for services, but there are grounds for pessimism on real progress.

\subsection{Consumer heterogeneity}

Existing research that computes price indexes for individual households shows clearly that individuals have quite different preference functions. The variation in individual price indexes among households within any group that has been examined (rich versus poor, elderly versus young, single versus married, and so forth) completely swamps the between group effects. Despite this, we ignore the long-standing distinction in the existing price index literature between democratic (households are weighted equally) and plutocratic (households are weighted according to their expenditure shares) aggregate price indexes, on the presumption that the alternative weighting patterns do not matter very much.

However, even if the aggregate weighting effects do not matter much, heterogeneity matters a great deal for quality change, new products, and even for selecting the items that should be priced within any CPI basic component. Existing work on quality change, such as hedonic price indexes, as well as existing estimates of consumer surplus for new products, explicitly rely on the presence of heterogeneity among consumers. One cannot work on these topics using the model of the representative consumer that underlies much of the current CPI. The representative consumer buys a car with 0.8 of an air conditioner and equipped with 0.1 manual and 0.9 automatic transmission. That representative consumer fiction simplifies the marginal analysis necessary to handle quality change in the CPI, but does such great damage to reality that the fiction is unappealing. Alternative approaches need to be explored. 


\section{Conclusions}

The future research agenda is rich. No doubt other topics will emerge as research proceeds, so this forecast is likely to be about as valid as other economic forecasts not without some usefulness, I would hope, but not all that prescient, either.

\section{References}

[1] E.R. Berndt, Z. Griliches and J.G. Rosett, Auditing the Producer Price Index: Micro Evidence From Prescription Pharmaceutical Preparations, Journal of Business and Economic Statistics 11(3) (1993), 251-264.

[2] S.D. Braithwait, The Substitution Bias of the Laspeyres Price Index: An Analysis Using Estimated Cost-of-Living Indexes, American Economic Review 70(1) (March 1980), 64-77.

[3] T.F. Bresnahan, Comment, in: The Economics of New Goods. National Bureau of Economic Research (NBER) Studies in Income and Wealth, (Vol. 58), T.F. Bresnahan and R.J. Gordon, eds, University of Chicago Press, Chicago and London, 1997.

[4] Commission of the European Communities, International Monetary Fund, Organisation for Economic Co-operation and Development, United Nations, and World Bank. 1993. System of National Accounts 1993. Office for Official Publications of the European Communities Catalogue number CA-81-93-002-EN-C, International Monetary Fund Publication Stock No. SNA-EA, Organisation for Economic Co-operation and Development OECD Code 309401 1, United Nations publication Sales No. E.94.XVII.4, World Bank Stock Number 31512.

[5] A. Deaton, Getting Prices Right: What Should Be Done? Journal of Economic Perspectives 12(1) (1998), 37-46.

[6] W.E. Diewert, Exact and Superlative Index Numbers, Journal of Econometrics 4(2) (May 1976), $115-145$.

[7] V.R. Fuchs, Production and Productivity in the Service Industries, in: NBER Studies in Income and Wealth, (Vol. 34), Columbia University Press, New York, 1969.

[8] R.J. Gordon, Addressing the Quality Change Issue in the Consumer Price Index: Comment, Brookings Papers on Economic Activity 0(1) (1997), 350-357.

[9] Z. Griliches, ed., Output Measurement in the Service Sectors, in: NBER Studies in Income and Wealth, (Vol. 56), University of Chicago Press, Chicago, IL, 1992.

[10] J.A. Hausman, Valuation of New Goods Under Perfect and Imperfect Competition, in: The Economics of New Goods, T. Bresnahan and R. Gordon, eds, Conference on Research in Income and Wealth, Studies in Income and Wealth 58: 209-237. University of Chicago Press for the National Bureau of Economic Research, 1997.

[11] P. Hill, The Measurement of Inflation and Changes in the Cost of Living. Prepared for the Conference of European Statisticians, Joint ECE/ILO Meeting on Consumer Price Indices, Geneva, November 24-27, 1997.

[12] M.E. Manser and R.J. McDonald, An Analysis of Substitution Bias in Measuring Inflation, 19591985, Econometrica (July 1988), 909-930.

[13] B.R. Moulton and K.E. Moses, Addressing the Quality Change Issue in the Consumer Price Index, Brookings Papers on Economic Activity 1 (1997), 305-349.

[14] W.D. Nordhaus, General Discussion of Addressing the Quality Change Issues in the Consumer Price Index, Brookings Papers on Economic Activity 0(1) (1997), 361-363.

[15] R.A. Pollak, The Consumer Price Index: A Research Agenda and Three Proposals, Journal of Economic Perspectives 12(1) (Winter 1998), 69-78.

[16] J.E. Triplett and R.J. McDonald, Assessing the Quality Error in Output Measures: The Case of Refrigerators, Review of Income and Wealth 23(2) (1977), 137-156. 
[17] J.E. Triplett, Escalation Measures: What is the Answer? What is the Question? in: Price Level Measurement, W. Erwin Diewert and C. Monmarquette, eds, Minister of Supply and Services Canada, Ottawa, Canada, 1983, pp. 457-482.

[18] J.E. Triplett, Hedonic Methods in Statistical Agency Environments: An Intellectual Biopsy, in: Fifty Years of Economic Measurement: The Jubilee of the Conference on Research in Income and Wealth, E.R. Berndt and J.E. Triplett, eds, University of Chicago Press for the National Bureau of Economic Research, Chicago, 1990.

[19] J.E. Triplett, Should the Cost-of-Living Index Provide the Conceptual Framework for a Consumer Price Index? in: Measurement of Inflation International Conference Volume, Cardiff University, Wales, Forthcoming. 